materially either in symptoms or in post-mortem appearances from what is noticed in horned cattle. Beyond this, we have only to say that there is no evidence whatever that the consumption of cattle-plague beef has in any case proved injurious to individuals or to communities which have been fed upon it. The discovery of "Rainey's bodies" in the flesh in inordinate numbers naturally led to the suspicion that they might be an early form of some entozoön capable of lodgment and development in the human system; but of this there is no proof, and so far as our present experience goes they are harmless to man. What these bodies are which have been so minutely described by Dr. Beale, and what relation they bear to cattle plague, are points for future science to determine. So far as inquiries have been prosecuted at present, they have been shown to have no peculiar relation to this disease, since they have been discovered in animals killed while in perfect health.

We cannot conclude without a word in commendation of the admirable manner in which the final report of the Cattle Plague Commissioners has been got up. Nothing can be more beautiful and truthlike than the illustrations with which the several reports forming the Appendix abound, executed in chromolithography in the very best style. The microscopic illustrations of Dr. Beale's report were drawn upon the wood by himself, and according to scale; so that not only may the exact dimensions of any object be easily ascertained with the aid of the scales of measurement appended to each plate, but the delineations themselves may be confided in for accuracy and truthfulness, as they could not have been relied on had this part of the work been entrusted to the hands of any professional draughtsman.

\title{
REVIEW IV.
}

Lectures on Mental Diseases. By W. H. O. SANkey, M.D. Lond., Fellow of the Royal College of Physicians ; Lecturer on Mental Diseases, University College, London; Proprietor of Sandywell Park Private Asylum; late Medical Superintendent of the Female Department of the Hanwell Asylum.

Ir is a matter of congratulation that psychological teaching has at length become an "institution" at some of our great metropolitan schools of medicine. University College has appointed one of her most worthy sons to occupy the new chair which she has created. There is a rumour that King's College, 
fired by a spirit of emulation, has entertained the same project, and will shortly carry it into effect; and at St. George's Hospital, twelve lectures on Insanity are given every winter session by Dr. Blandford. Thus is being supplied a deficiency which has long been greatly needed.

Since the year 1843, when Dr. Conolly delivered a clinical course at Hanwell, we are not aware that any steps have been taken by which students might acquire some practical knowledge of mental diseases. A few occasional pupils at Bethlehem and St. Luke's have kept alive the fact tht two insane picturegalleries are still open, upon a trifling fee, for a morning stroll to the professional dilettanti. But these two hospitals have failed to furnish any systematic teaching worthy in the one case of its great endowments, and in the other of its able medical staff.

The natural result, therefore, of this state of things has been (we say it with all due respect, and we speak advisedly) an ignorance on the part of general practitioners in respect of lunacy which is hardly to be credited by any one who has not had an opportunity of noticing the fact. This ignorance shows itself not only in a deficient acquaintance with the laws of lunacy as evidenced by medical certificates, but in a want of familiarity with the symptoms of special disease. Of nothing can this be more truly said than of the general paralysis of the insane, or (as Dr. Sankey prefers to term it) of general paresis. We constantly hear of patients being admitted into asylums, far advanced in this most fatal malady, of whom able and well-educated practitioners have certified that their attack is "recent" and "uncomplicated with any form of paralysis or epilepsy."

But what can the verbal pictures of Drs. Bucknill and Daniel Tuke, or of Dr. Sankey, do towards familiarising students with insanity, if they are not accompanied by objective teaching? And how is this objective teaching to be obtained? Fees will not procure admission into county and borough asylums, where, for the most part, the visiting justices regard them as provinces not to be trespassed upon by any outsiders, who might sometimes call in question the wisdom of committees, or smile at magisterial self-importance. This difficulty must be faced by any future professor of psychology at a metropolitan school, unless he is officially connected with Bethlehem or St. Luke's.

Through the courtesy of the Visiting Committee and the physicians to the Sussex County Asylum, Dr. Sankey was enabled to take his pupils from University College to Hayward's Heath, where Dr. Lockhart Robertson instructed them in general asylum management, and brought under their notice 
the useful and interesting cases at that time under treatment. Dr. Paul, of Camberwell House Asylum, has done a similar good office, and thus smoothed away some of the difficulties of the new professor in Gower Street.

The lectures which Dr. Sankey delivered he now gives to the profession in a published form. While there is much originality in many of his views, and much to be commended in the manner in which he elucidates them, there are things of great importance which he has altogether overlooked, and which are strikingly "conspicuous by their absence." We can understand, for example, how a general practitioner, who perhaps is more frequently brought in contact with that form of insanity which is allied with the puerperal state than any other, would expect to find some help from a lecturer who for years has been connected with the female department of a great asylum. And yet there is no allusion to puerperal mania beyond a mere statement of the general fact that lying-in women are subject to an abnormal something which takes its name from a condition by which the human family is enlarged and multiplied. Dr. Sankey's rigorous exclusiveness in classification has led him into this strange omission, and into others which justify us in thinking that these lectures are more suited for those who have some previous knowledge of the subject, and propose to devote themselves entirely to the specialty of which he treats, than for those to whom a case of insanity will in the nature of things be rare and exceptional. Their value to the profession at large is thus greatly lessened.

And yet we think there is much to be said for the simple and uncomplicated classification which our author recommends. It is beyond a doubt that in general medicine students are constantly embarrassed by the elaborate trifles by which their teachers seek to point out differences of no appreciable value, and which, when discerned, exercise no influence either upon prognosis or treatment. The great error which authors have committed in classifying mental diseases, has been that of coining some distinctive name from some prominent symptom; whereas the prominent symptom is a mere accident arising in the course of the malady, giving us no sort of clue to the general psychological or pathological condition of the patient. Thus, varieties have come to be exalted into species, and the element of simplicity has been causelessly banished from nearly every classification :

"To separate one species of disease from another, I hold that it is necessary to prove that one has a different origin, a different progress, and a different termination." (P. 57.)

With a view of helping us out of our difficulties, the distin- 
guished physician of an Asylum proposed to us three years ago a "Rational and Practical Classification," embracing twenty-six different species of disease. He must have had in remembrance that passage of old Burton (quoted by Dr. Sankey) in his 'Anatomy of Melancholy,' where he says-"The fourand-twenty letters make no more variety of words in divers languages than melancholy conceits produce diversity of symptoms in several persons." Or he must have recently perused the 'Leçons Orales' of Guislain, where he says (in words also quoted by Dr. Sankey), "Vingt-trois formes de manie, sans compter plusieurs formes composées non indiquées, voilà, me direz-vous peut-être, un bagage symptomalogique passablement lourd pour la mémoire."

Everywhere, and most consistently, Dr. Sankey protests against the useless verbiage of name-inventors in classification, avowing that "their efforts have tended rather to complicate the subject than to render it more easy to comprehend." He even goes so far as to state that, according to his experience, melancholia and mania are simply stages of one disease; that it will be found on investigating the history of every case of primary mania, that the first symptom was depression of spirits, formation from one state to the other. This view had been previously advanced by Guislain, Neümann, and Griesinger; but it has never been so dogmatically stated (on his own ad. mission) as by the author of the Lectures under consideration, who supplements his declaration by the proposition, that in secondary attacks (so-called) of mania, the primary disease has never quite subsided if melancholia has not again initiated the seizure.

"I think the study of certain of these secondary or recurrent -cases proves them to be mere gradations in the absoluteness of the recovery from the primary attack; the progress of the morbid phenomena becomes moderated and intensified at irregular periods, but never actually ceases. They are cases of chronic insanity, therefore, and differ only in having a more marked lucid interval between the paroxysms." (P. 109.) Instead, therefore, of the "Rational and Practical Classi-
fication," embracing twenty-six varieties, Dr. Sankey gives us one much more rational and practical, from whose simplicity are evolved only two morbid species, viz.-1. Insanity; 2. General Paresis. But mental symptoms occur also as epiphenomena in certain cases of epilepsy, giving us - 3 . Epileptic Mania. These are the absolute diseases, and together with the imperfect manifestation of mind, as in idiocy, and with 
decay, as in old age, constitute the sum of all we have to study. With respect to ordinary cases of insanity, the phenomena exhibited in primary attacks are, chiefly-depression, morbid apprehensions, illusions, constituting an attack of melancholia. These phenomena may terminate- 1 , in health; 2 , in death; 3 , in mania; 4 , in chronic insanity. The melancholia may remain melancholia, which name-mongers will baptize and classify according to the character and form of the morbid apprehensions. Or it may become acute or chronic mania, according to the measure of duration and intensity. These also may draw largely upon the fancies of lovers of nomenclature. Under all the above conditions, when the tendency is neither towards death nor recovery, it is towards imbecility or dementia.

It will be seen from the above classification that our author regards general paresis as a distinct morbid species, not answering to Dr. Skae's definition as " a form of insanity complicated with general paralysis, or as a general paralysis complicated with insanity." In this opinion he is supported by Parchappe, Jules Falret, Delasiauve, Salomon, and others.

We prefer giving Dr. Sankey's arguments for isolating general paresis from diseases of the mind proper in his own words.

"1st. It appears to me that if the paretic symptoms are mere epiphenomena, then the duration of the disease should be longer in general paresis than in insanity generally; but the reverse is the fact.

" 2 nd. If the motor symptoms are merely, as it were, engrafted upon ordinary cases of insanity, then cases of second and third attack should be equally liable to have the paretic symptoms engrafted upon them as first attacks. But such is not found to be the fact.

"3rd. If the paretic symptoms are epiphenomena, they should occur as frequently among the old inmates of asylums as among the more recent cases. If, indeed, these symptoms are to motility what imbecility is to the intellectual faculties, we ought to find general paresis more frequently developed in the old cases than in the recent; but such is not the case.

" 4 th. If the disease is identical with other forms of insanity, and the paresis a mere accident, then the frequency of the predisposing causes should be the same in all cases; whereas I found in my paretic cases hereditary predisposition existed in $14 \frac{1}{2}$ per cent. instead of 20 per cent. among females, and $17 \frac{1}{2}$ per cent. instead of 22 per cent. among males. And in examining into the evidence of hereditary predisposition in paresis, there was found to be evidence of paralytic symptoms in many of those from whom the predisposition came.

" 5 th. If general paresis is one and the same disease as insanity, 
then in those instances in which several members of a family are insane it should happen that some should be found with paretic symptoms, and some without. There were fifty-five patients in Hanwell related by blood to other patients also under treatment. There was but one paretic, who was an epileptic, with motor paresis, the niece of whom was also in the asylum.

"Lastly. General paresis, besides the difference which it manifests to insanity generally, in affecting the sexes, the different classes of society, and different localities, to a different degree, also appears to affect individuals of a peculiar temperament. Among the patients affected with it, we find chiefly those who have lived a fast life; reckless, imprudent individuals, who seem from their history to have been swayed through life by their lusts and passions."

Dr. Sankey admits himself that the above arguments are not conclusive; but he thinks that they strongly favour the opinion of the specific nature of the disease as a distinct species rather than a variety of mental alienation. He thinks also that sexual indulgence is one of the chief factors in producing this hopeless malady, and that the predisposition to it of the different classes of society is, in the order of sequence, that also of the subjugation of the animal passions, viz.- 1 , males of the lower classes ; 2 , males of the upper classes ; 3 , females of the lower classes; 4, females of the upper classes. Among the latter, Dr. Conolly distinctly states that in the whole of his large experience he never met with a single case.

Our author graphically describes the three stages of general paresis, and the various modes of its invasion. In alluding to the gradual loss of excito-motory power, he confirms the opinion of Dr. Bucknill as to the effect of tickling the soles of the feet: "In ordinary paralysis there is no loss of excito-motory sensibility, while in general paralysis there is a great loss of this power." We are bound to state that our own experience does not enable us to endorse unequivocally the statements of these two psychologists; and we may add, that the opinion of MM. Brierre de Boismont and Duchenne de Boulogne upon this subject is directly at variance with that of their two English confrères. With respect to the morbid anatomy of general paresis, Dr. Sankey agrees with Wedl and Rokitansky in thinking that there is in the cerebral substance an overgrowth of connective tissue on the outer walls of the little arteries and veins, but that this pathological condition is by no means confined to this specific disease. He does not think we are yet in a position to demonstrate any distinct alteration in the nerve-elements or nervous structure of the brain, but.inclines to believe that a morbid condition of the capillaries of the cortical substance is the real explanation of general paresis. 
While the amount of alteration bears no relation to the date of disease, degree of imbecility, or impaired motility, this abnormal appearance exists but very rarely in any other form of mental disease. Rokitansky and Wedl, however, dissent from this view. Dr. Sarkey thus expresses himself upon this point:

"The capillaries enter the ecrtical substance of the brain from the under surface of the pia mater in the direction of a right angle to the circumference. There appear to be two kinds of them, one of which is short, and divides into a tuft of minute capillaries close to the peripheral surface of the brain; and the other is larger and pierces deeper, and then divides in the same manner. The trunk of the larger artery especially is found at places curiously twisted in cases of general paresis; and I have found some disposition to twisting or varicosity in every case of the disease I have hitherto examined. All degrees of tortuosity are to be found in different brains, and great variety in degree in one brain-from the absence of straightness to the most complicated knots. My own examinations of the capillaries in about twenty cases of insanity, and seven of which were from patients who died of general paresis, lead me to the conclusion that the capillaries of the cortical substance are more or less diseased in every case of general paresis." (Pp. 174, 175.)

We have dwelt thus upon general paresis, because it appears to us that Dr. Sankey has handled the subject in an able manner, and because of its growing importance, by reason of increasing frequency.

In treating of the general predisposing and exciting causes of insanity, Dr. Sankey does not fail to point out the many disturbing influences which lessen the value of statistical conclusions, and should render us sceptical about all dogmatic teaching based upon formulated tables. It is difficult to isolate the factors of disease, and determine the relative measure of physical and moral causation. Under the large and general term of "civilisation" the material and immaterial influences are happily blended; and in spite of much which has been said and written to the contrary, we are driven to the inevitable conclusion "that the wealthier, and therefore surely the more educated and higher civilised class, is less liable to insanity than the middle and lower class."

Wherever men are grouped together in large masses-as where civilisation marches-there are grouped also the social vices as well as the social virtues. Ignorance, dirt, intemperance, promiscuous intermarrying, sexual excesses, and sensuality of every kind, are (as Dr. Sankey happily expresses it) the "campfollowers" of intellectual progress. They go where civilisation goes, and there is no staying their influence; and the result is, that the proportion of pauper insane to pauper sane is as 
1 to 50 , while the proportion of non-pauper insane to non-pauper sane is as 1 to 3982 .

We cannot bestow the highest praise upon the style in which these lectures are written. There are many obscure and many slipshod sentences which are quite unworthy of an erudite physician. The first lecture might well have startled his class, for Dr. Sankey presents to them a sketch of mental science which it is by no means easy to understand. Nor does he give them any very cheering accounts of therapeutic agents in the treatment of disease. He has little or no faith in opium, or digitalis, or tartar emetic, or Indian hemp. Mustard baths and shower baths seem to him to be the best sedatives. But the entire subject of therapeutical treatment is dismissed in a page and a half; whereas he has devoted thirty-seven pages to the moral agency by which insanity may be controlled and regulated. Its legal relations are summed up in a very useful chapter, which may be read with profit by every practitioner.

If Dr. Sankey has failed to produce a course of lectures equal in their completeness to his known attainments, he has at least given us evidence of much painstaking and research.

\section{Review V.}

The Harveian Oration, 1865. By Henry W. Acland, M.D., F.R.S., Regius Professor of Medicine in the University of Oxford. Macmillan \& Co. 1865.

The Harveian Oration was last year, for the first time, pronounced in English. Harvey, were he alive, would probably not disapprove the innovation. So keen and forward-reaching a spirit would have fully appreciated the convenience and the freedom which the natural language of use and common life gives for the adequate discussion of the discoveries and subtle ideas ever newly emerging, as our knowledge of nature is enlarged, deepened, and corrected. Yet, perhaps, some not altogether groundless regrets might have passed through his mind at seeing, in one instance after another, the disuse of that powerful and accurate instrument of expression which he employed, and which in the hands of those who know how to use it, as many did in his day, is no contemptible aid for securing precision and directness of speech, even in scientific subjects, while it is almost incomparable in clothing memorable thoughts in memorable forms, and in impressing the attention by the force which is given by terseness, apt felicity, and the majesty of severe and well-weighed statement. To be able to 